\section{ATRIOVENTRICULAR VALVE REPAIR USING EXTERNALLY ADJUSTABLE FLEXIBLE RINGS}

Initial results obtained with a new flexible ring, adjustable from outside of the heart after interruption of extracorporeal circulation, are presented. Twenty-five rings have been inserted in 20 patients, 14 in the mitral position and 11 in the tricuspid position. In 8 of the 14 patients receiving mitral annuloplasty, other standard mitral valve repair techniques were used. Adjustment, assisted by intraoperative transesophageal color Doppler echocardiography, was done for $10(71 \%)$ of the mitral rings and for 8 (73\%) of the tricuspid rings. Residual mitral regurgitation disappeared or became minimal in $9(90 \%)$ patients, and a mild regurgitation remained in 1. In all patients who received tricuspid rings regurgitation was abolished after the adjustment. There was no hospital or late mortality. After a maximum follow-up of 6 months results are comparable in the tricuspid and mitral positions and echocardiographic evaluation revealed stable competent valves in all patients but one, who underwent reoperation because of failure of a mitral valve chordae shortening procedure. The use of externally adjustable rings for the mitral and tricuspid valves is a safe alternative for atrioventricular valve annuloplasty and has the additional advantage of reducing postrepair regurgitation. (J THORAC CARDIOvasC SURG 1995;110:1333-7)

J. Q. Melo, MD, PhD (by invitation), M. Abecasis, MD (by invitation),

J. Neves, MD (by invitation), L. Bruges, MD (by invitation), M. Ferreira, MD (by invitation), M. J. Rebocho, MD (by invitation), R. Ribeiras, MD (by invitation), M. Canada, MD (by invitation), R. Seabra-Gomes, MD, $\mathrm{PhD}$ (by invitation), and Manuel Machado-Macedo, MD, PhD, Carnaxide, Portugal
A nnuloplasty of the mitral and tricuspid valves with the use of prosthetic rings is done with extracorporeal circulation and consequently evaluation of the size or the adjustment of the prosthetic ring required to reduce the enlargement of the anulus is done on an arrested and flaccid heart. Because of this, the measurements are often inaccurate and residual valve regurgitation may occur.

This report introduces a new concept of prosthetic ring annuloplasty of the mitral and tricuspid valves. To preclude the inaccuracies that result from adjustments of the ring being made in a nonfunc-

From the Departments of Cardiothoracic Surgery and Cardiology of the Hospital de Santa Cruz and the Instituto do Coração, Carnaxide, Portugal.

Read at the Seventy-fifth Annual Meeting of The American Association for Thoracic Surgery, Boston, Mass., April 23-26, 1995.

Address for reprints: João Q. Melo, Serviço de Cirurgia Cardiotorácica, Hospital de Santa Cruz, Avenida Professor Reynaldo dos Santos, Carnaxide 2795 Linda-A-Velha, Portugal.

Copyright $(\mathbb{C} 1995$ by Mosby-Year Book, Inc.

$0022-5223 / 95 \$ 5.00+0 \quad \mathbf{1 2 / 6 / 6 7 7 3 6}$ tioning heart, a partial and flexible prosthetic ring was designed that can be adjusted from the outside of the heart after extracorporeal circulation has been discontinued and stable hemodynamics attained. This enhances the results of the annuloplasty procedure by reducing the degree of postrepair regurgitation. The ring has two inner sutures that pass to the outside of the heart. These sutures are protected by a rigid tube, which is removed before the fixation sutures are tightened. Adjustment of the dimensions of the ring is done before the chest is closed with the aid of transesophageal color Doppler echocardiography.

The initial results in 20 patients in whom this type of ring has been implanted are presented.

\section{Material and methods}

Between May and October of 1994, 20 consecutive patients, 15 female and 5 male, with a mean age of 45 years (range 7 to 70 years), underwent elective mitral (11) or tricuspid (1) valve repair, or both (9). This project was approved by the appropriate hospital committee and specific informed operative consent for implantation of this device was obtained from each patient. 


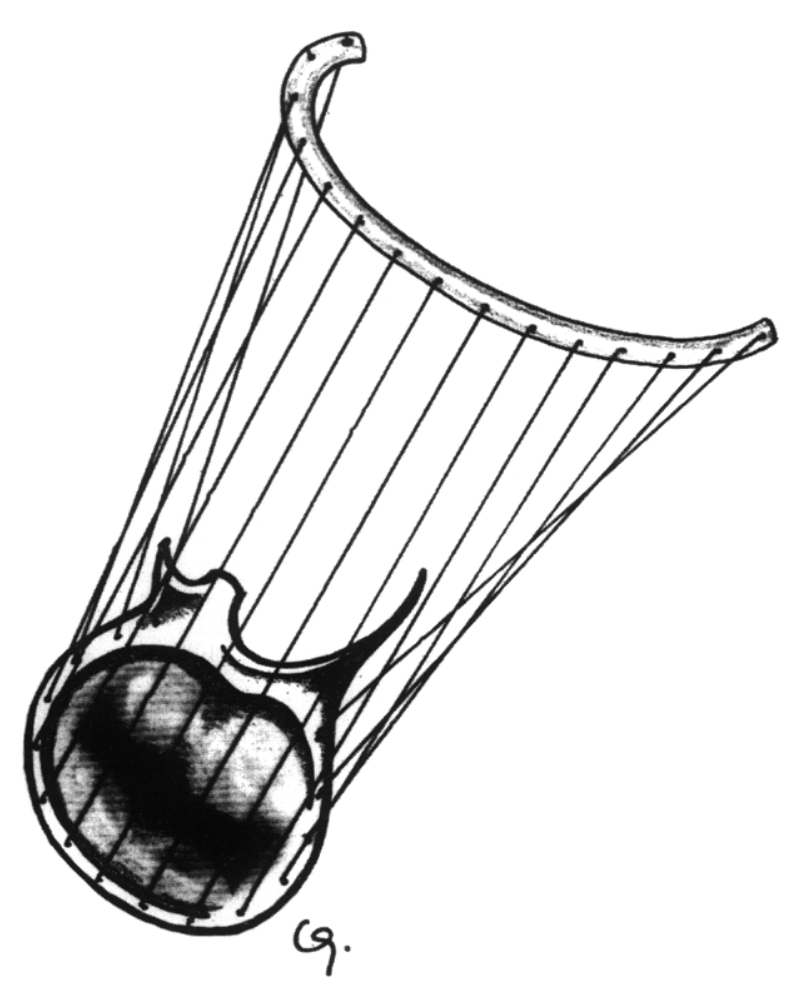

Fig. 1. Adjustable and flexible prosthetic ring.

Six patients were in New York Heart Association functional class II, 13 in class III, and 1 in class IV. The cause of the disease was rheumatic in 12 patients, degenerative in 7, and congenital (Ebstein malformation) in 1. Valves affected were the mitral in 7 patients, the mitral and tricuspid in 6 , the mitral and aortic in 2 , and the mitral, tricuspid, and aortic in 3. A tricuspid pathologic condition was isolated in 2 .

Mitral regurgitation was pure in 8 patients and associated with stenosis in 11. Mitral and tricuspid valve regurgitation was classified in grades 0 to 3 by the maximum area of the colored jet of regurgitation in the atrium. ${ }^{1}$ The average grade of mitral insufficiency was 2.2. All tricuspid lesions involved pure regurgitation, with a mean grading of 2.5 .

Fifteen patients were in atrial fibrillation, two had had previous thromboembolic events, and three had a history of endocarditis. One patient had single-vessel coronary artery disease and another an atrial septal defect. Seven patients had had a previous mitral valve operation consisting of closed commissurotomy.

In all patients intraoperative transesophageal Doppler echocardiography was done. Patients underwent operation with the use of standard cardiopulmonary bypass. Myocardial protection was achieved with cold crystalloid cardioplegic solution infused by antegrade and retrograde routes at 20 -minute intervals.

Nine patients received a mitral ring, six had a tricuspid ring annuloplasty, and five had both mitral and tricuspid prosthetic ring valve repairs. Table I shows the associated operative procedures. The mitral valve repair was isolated
Table I. Associated operative procedures

\begin{tabular}{lr}
\hline \multicolumn{1}{c}{ Procedures } & $N$ \\
\hline Mitral valve & \\
Repair & 17 \\
$\quad$ Replacement & 2 \\
Tricuspid valve & \\
$\quad$ Repair & 12 \\
Aortic valve & 1 \\
$\quad$ Repair & 3 \\
$\quad$ Replacement & 1 \\
Coronary artery bypass & 2 \\
Maze III operation & 2 \\
Left atrium isolation & \\
\hline
\end{tabular}

annuloplasty in six patients and associated with other procedures in eight, namely, commissurotomy (8), leaflet mobilization (8), shortening of chordae (3), calcium removal (5), chordae translocation (1), papillary muscle elongation (3), and resection of posterior leaflet chordae (1). The tricuspid valve operation was, in all cases, annuloplasty.

Our ring is made of polytetrafluoroethylene and has two drawstrings inside. Seven sizes are available, ranging from 6 to $12 \mathrm{~cm}$ in $1 \mathrm{~cm}$ increments (Fig. 1).

In the mitral position the technique of implantation is similar to that described for other posterior rings. Interrupted 2-0 polypropylene stitches are inserted from the left fibrous trigone to the right fibrous trigone, along the posterior mitral anulus and passing through the ring. After the fixation sutures are tied, the adjusting inner strings are passed from inside to the outside of the heart through the left fibrous trigone. They exit the heart near the base of the noncoronary leaflet of the aortic valve (Fig. 2 , left). In tricuspid position the ring is implanted from the triangle of Koch to the level of the central fibrous body, where the adjusting sutures are passed to the pericardial cavity, outside the heart (Fig. 2, right).

After cessation of cardiopulmonary bypass and when stable hemodynamics are achieved, assessment of the repair is done by transesophageal echocardiography. In cases of residual mitral or tricuspid regurgitation, the size of the atrioventricular ring is adjusted by tightening and cinching the drawstrings outside of the heart. The simultaneous echocardiographic evaluation guides the proper amount of annular shortening necessary to lessen or abolish the regurgitation interval, avoiding excessive reduction of the valvular area.

\section{Results}

A total of 25 atrioventricular rings were implanted, 14 in mitral position and 11 in tricuspid position. The mean durations of extracorporeal circulation and aortic crossclamping were 114 minutes (range 63 to 203 ) and 87 minutes (range 44 to 174 ), respectively.

After completion of the procedure transesophageal color Doppler echocardiography showed no signs of regurgitation in $4(29 \%)$ of the repaired 

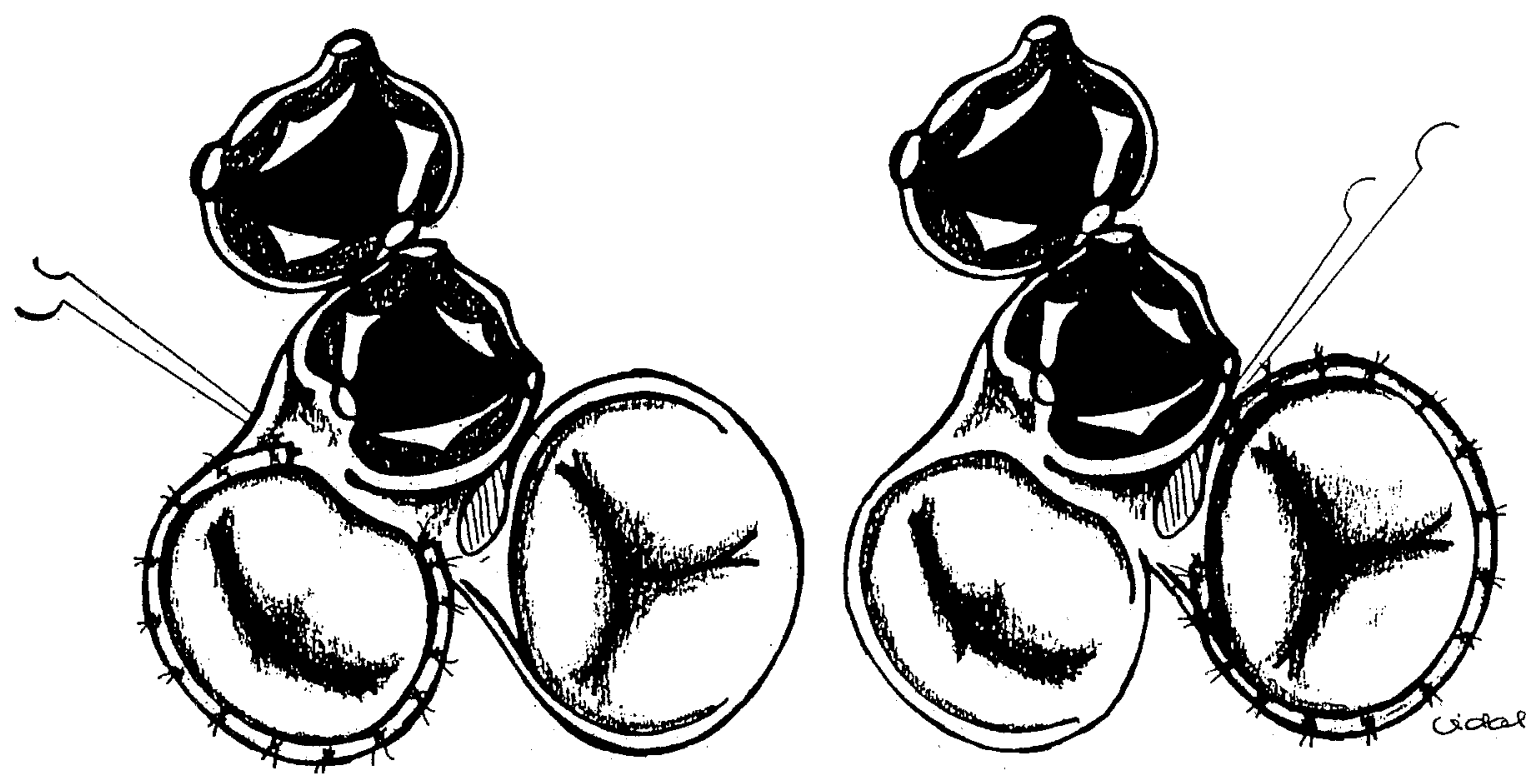

Fig. 2. Annuloplasty ring implanted in mitral (left) and tricuspid (right) valves showing adjusting strings passing to outside of heart through left fibrous trigone and central fibrous body, respectively.

mitral valves or in $3(27 \%)$ of the tricuspid valves; thus these required no adjustment of the ring. Table II shows the sizes and adjustments of the prosthetic rings done in the remaining cases. After adjustment the residual mitral valve regurgitation was reduced to minimal or no regurgitation in $9 .(90 \%)$ patients and to mild in $1(10 \%)$. Moderate-grade tricuspid regurgitation, present in $8(73 \%)$ patients, disappeared in all cases after the adjustment of the ring.

No patient required reoperation for replacement of the valve or because of bleeding. One patient required an early reoperation because of failure of the chordae shortening procedure of the mitral valve repair. In this patient we could verify that the ring was in a good position after the adjustment made in the first operation.

There have been no instances of thromboembolic events or damage to the conduction tissue. After a mean intensive care unit stay of 62 hours and a mean hospital stay of 10 days, all patients were discharged. There was no hospital or late mortality.

Echocardiographic evaluation at discharge and follow-up (maximum duration of 6 months with a mean of 4 months) showed values identical to those obtained after the intraoperative adjustment of the ring.

\section{Discussion}

Current techniques of mitral and tricuspid valve annuloplasty are associated with a considerable prevalence of residual regurgitation after valve re-
Table II. Echo assessment of atrioventricular valve repair

\begin{tabular}{|c|c|c|c|c|}
\hline \multirow[b]{2}{*}{ Regurgitation } & \multicolumn{2}{|c|}{ Intraoperative } & \multicolumn{2}{|c|}{ Postoperative } \\
\hline & $\begin{array}{c}\text { Before } \\
\text { adjustment }\end{array}$ & $\begin{array}{c}\text { After } \\
\text { adjustment* }\end{array}$ & $\begin{array}{c}\text { Dis- } \\
\text { charge }\end{array}$ & $\begin{array}{l}\text { Follow- } \\
\quad \text { up }\end{array}$ \\
\hline \multicolumn{5}{|l|}{ Mitral (\%) } \\
\hline None & 62 & 90 & 90 & 90 \\
\hline Mild & 29 & 10 & 10 & 10 \\
\hline Moderate & 10 & 0 & 0 & 0 \\
\hline \multicolumn{5}{|l|}{ Tricuspid (\%) } \\
\hline None & 20 & 90 & 100 & 100 \\
\hline Mild & 80 & 10 & 0 & 0 \\
\hline Moderate & 0 & 0 & 0 & 0 \\
\hline
\end{tabular}

*Extracardiac adjustment of the ring after cardiopulmonary bypass.

pair. It is well known that this prevalence is higher in patients with rheumatic disease than in those with ischemic or degenerative disease. ${ }^{2}$ This is because of the more deformed valves found in rheumatic disease and because most current procedures used to test the efficiency of the repair are done in the nonbeating or nonworking heart.

The method we developed provides the opportunity of adjusting the dimensions of the annuloplasty ring after extracorporeal circulation is discontinued. This provides physiologic conditions for the final adjustment of the dimensions of the ring, inasmuch as the adjustment is done in a beating, working heart. The procedure is monitored with transesophageal color Doppler echocardiography, with tighten- 
ing of the drawstrings of the ring being done in a manner such that residual regurgitation is reduced or abolished without creating stenosis.

The possibility of extracavitary adjustment in heart operations was described for the correction of tricuspid insufficiency by Alonso-Lej and Cofino $^{3}$ in 1974 and by Alonso-Lej in 1988. These surgeons gained external control of suture annuloplasty by taking both ends of the suture through the wall of the right atrium after removal of the cannula in the venae cavae. Kurlansky, Rose, and Malm $^{5}$ also reported their experience with the method, but no long-term results have been published. Laks and Billingsley, ${ }^{6}$ in 1989, reported on the technique for an adjustable atrial septal defect in partial Fontan procedures. To our knowledge, there are no further reports on externally adjustable intracardiac devices.

Our technique is anatomic and safe. The shortening of the ring is done through the fibrous skeleton of the heart, causing no deformities of the heart cavities. It allows the use of large rings and has the capability of maintaining the three-leaflet structure of the tricuspid valve and the two-leaflet structure of the mitral valve. Reduction of the size of the anulus is achieved by the sum of minimal retractions of every stitch of the ring insertion and, after the adjustment, by the shortening of the space between each stitch.

Control of the final dimensions of the ring is done by intraoperative transesophageal color Doppler echocardiography. The superiority of this method over the commonly used method of intraatrial finger palpation was first reported by Simone and colleagues ${ }^{7}$ in adjustable suture annuloplasty of the tricuspid valve. Our results show that this technique is safe and effective.

Residual mitral regurgitation disappeared or became minimal in nine $(90 \%)$ patients, and a mild regurgitation remained in one. In all patients undergoing tricuspid annuloplasty, regurgitation was abolished after the adjustment.

In conclusion, the external fine adjustment of atrioventricular valve annular rings, in the working heart, provides an additional feature to improve the results of annuloplasty techniques. Long-term results will provide the necessary information on the efficacy of the method.

We gratefully acknowledge Junta Nacional de Investigacão Cientifíca and Fundação Gulbenkian for their support of our research program and R. Vidal, RN, for the skillful drawings.

\section{REFERENCES}

1. Yoshida K, Yoshikawa J, Yamaura Y, Hozumi T, Akasaka T, Fukaya T. Assessment of mitral regurgitation by biplane transesophageal color Doppler flow mapping. Circulation 1990;82:1121-6.

2. Deloche A, Jebara VA, Relland JY, et al. Valve repair with Carpentier techniques: the second decade. J THORac Cardiovasc Surg 1990;99:990-1002.

3. Alonso-Lej F, Cofino JL. Reparacion fisiologica de la insuficiencia tricuspide: la anuloplastia circular con control externo. Cirug Cardiovasc 1974;3:5-11.

4. Alonso-Lej. Adjustable annuloplasty for tricuspid insufficiency. Ann Thorac Surg 1988;46:368.

5. Kurlansky P, Rose EA, Malm JR. Adjustable annuloplasty for tricuspid insufficiency. Ann Thorac Surg 1987;44:404-6.

6. Laks H, Haa GS, Pearl MJ, et al. The use of an intraatrial communication in patients undergoing the Fontan and other definitive heart procedures. [Abstract]. Circulation 1988;78(Suppl):II357.

7. Simone RD, Lange R, Tanzem A, Gams E, Hagl S. Adjustable tricuspid valve annuloplasty assisted by intra-operative transesophageal color Doppler echocardiography. Am J Cardiol 1993;71:926-31.

\section{Discussion}

Dr. D. Craig Miller (Stanford, Calif.). I congratulate this group for rejuvenating an old method, which was initialy applied to the tricuspid valve by Fernando Alonso-Lej in Zaragoza, Spain, in 1973. This concept has also been applied to the right-sided atrioventricular valve by other investigators in Spain, including Dr. Norberto DeVega, and North America, including Jim Malm, Eric Rose, and Bob Frater in New York.

This current group has taken this idea to the left-sided atrioventricular valve and used an externally adjustable ring. This is, of course, equivalent to a Puig-Massana ring, which is tightened down intraoperatively, or to the "Designer" ring as devised by a new member of this Society, Dr. Sara Shumway, and by Bruce Reitz at Hopkins. They had a drawstring of umbilical tape, on the tube graft to drawn down on the annular circumference intraoperatively, but not postoperatively.

I would like to compliment the authors for using a partial ring on the left side, and the questions I have relate to why this is necessary. You used the drawstrings in $70 \%$ to $75 \%$ of cases on the left and the right side. Before you went to this technique, I am sure you did not have to reoperate on $75 \%$ of the patients to do another adjustment or re-repair.

Dr. Melo. I am aware of the precursor work of AlonsoLej, which we acknowledge in our manuscript. What he did was a suture annuloplasty of the tricuspid ring with adjustment through the lateral wall of the right atrium. The idea of adjusting the annuloplasty from outside goes back to 1973. The goal of adjusting the rings is to have a reduction of the anulus, a smaller reduction, to achieve a two-leaflet structure in the mitral valve and a three-leaflet 
structure in the tricuspid valve. This is always extremely difficult in the arrested, flaccid heart. The potential of performing minor adjustments with our ring enables us to obtain this goal. Only in the future we will know if this feature will improve the results of mitral and tricuspid annuloplasty.

Dr. Miller. That leads to my next question. This is an uncontrolled circumferential or at least partial tightening or cinching. Most of us prefer a more precise and measured sort of approach in which plication is done just in certain areas and not diffusely, as is the case with the Puig-Massana ring, Sculptor ring, or your ring. Why do you think your method is better?

Dr. Melo. The basic mechanism is adjustable to each individual valve, that is the major annular reduction is done by the sutures used to implant the ring along the anulus of the posterior leaflet, and this is the major adjusting mechanism. The eventual remaining decrease in dimension is achieved by cinching the inner sutures but those are only minor adjustments.

Dr. Miller. I see: the majority of the plication is done by the suture placement.

Next, 12 out of 20 patients had rheumatic valve disease and most were female. How would your method apply to other populations with mostly myxomatous valve disease and more men? What are the inclusion criteria?

Dr. Melo. The first selection criterion was the pa- tient's acceptance. All patients were oeprated on after approved operative consent was obtained containing the information that this was a new procedure. A few patients did not accept it. Second, we selected patients in whom other alternative procedures have not had good results, so this was a difficult group of patients in whom the situation was appropriate for the operation.

As you know, the results of mitral valve repair in patients with rheumatic lesions are worse than results in patients with ischemic conditions. Since the initial 20 patients, we have been doing this operation in patients with ischemic and degenerative conditions with even better results than before in the mitral position.

Dr. Miller. Do I then infer that you use the technique universally now, in ischemic, myxomatous, and rheumatic disease?

Dr. Melo. No, we do not use it universally because we depend still on authorization from the patient.

Dr. Miller. My final question is this: have you ever caught the drawstring with the plication suture such that you cannot cinch it down?

Dr. Melo. No, because in our method that cinching mechanism is marked.

Dr. Miller. You have never bagged it with one of the needles?

Dr. Melo. No.

\section{1-800-55-MOSBY}

This number links you to the full text of articles published in over 25,000 journals, including all Mosby journals. MOSBY Document Express $^{\circledR}$, a rapid response information retrieval service, provides quick turnaround, 24-hour availability, and speedy delivery methods. For inquiries and pricing information, call our toll-free, 24-hour order line: 1-800-55-MOSBY; outside the United States: 415-259-5046; fax: 415-259-5019; E-mail: mosbyexp@class.org. 